\title{
IS HABITAT PATTERNING THE RISK OF LIFESTYLE DISEASES AMONG AO NAGAS?
}

\author{
Imkongtenla Pongen
}

PhD Scholar, Physiological Anthropology Laboratory, Department of Anthropology, University of Delhi110007, India.

\author{
Satwanti Kapoor \\ Professor, Department of Anthropology, University of Delhi-110007, India.
}

\begin{abstract}
Introduction: An increased risk of lifestyle diseases in populations with rapid nutritional transition and urbanization, its patterning in urban-rural continuum with clusters of risk factors has been documented in various populations but there has been limited data on tribal population in India.
\end{abstract}

Objective: To compare the distribution pattern of risk factors associated with lifestyle diseases among Ao Nagas residing in different habitats: city, town and villages in Nagaland, India.

\section{Methodology:}

Design: Population based cross-sectional study

Setting: Delhi and Mokokchung town and its adjoining villages in Nagaland.

Population: 1250 Ao Nagas, aged 20-49 years

Protocol: WHO Stepwise approach to Surveillance of Non-communicable diseases (STEP1 and STEP 2).

Findings: WHO STEP 1 risk factors, viz., low physical activity and alcohol consumption; STEP 2 risk factor,viz., overweight and obesity were significantly higher among city dwellers. Tobacco consumption (STEP 1 risk factor) was significantly higher among town dwellers. However, villagers were found to be significantly more hypertensive (STEP 2 risk factor) than their urban counterparts. Clustering of $\geq 3$ risk factors for lifestyle diseases were more likely to be prevalent among the city dwellers as compared to town and village dwellers.

Implications: This study calls for careful implementation of different strategies to combat the burden of lifestyle diseases in the population both in rural and urban areas considering a comprehensive approach integrated at the primary healthcare sector. Market penetration of smokeless tobacco products in town and villages should be a concern for the policy makers. Binge drinking and alcohol abuse in the population despite Nagaland been declared as a 'Dry state' warrants rigorous and timely health intelligence as prohibitive measures.

KEYWORDS: Ao Nagas, NCDs, lifestyle diseases, Risk factors, Nagaland, WHO STEPs 


\section{INTRODUCTION:}

Lifestyle is a pattern of individual practices and personal behaviors that are related to elevated or reduced health risk. Its causes range from childhood determinants to personality makeup to the cultural, physical, economic, and political influences (Detels et al, 2002). Changes in lifestyle behaviors in recent times have increased chronic disease risk accounting for $60 \%$ global deaths. Such diseases are a group of 'silent killers' and are often grouped as "Lifestyle Diseases" (Murray et al, 2012).

These diseases reflect a rural-urban continuum through differences in socio-cultural and environmental conditions. $19^{\text {th }}$ century research on infectious diseases mediated through higher density of population proposes a theory of 'urban penalty', while $20^{\text {th }}$ century research on infant and child mortality and nutritional status mediated by better access to healthcare pinpoints an 'urban advantage' (Harpham,2009).Urbanization may increase the risk factors of NCDs (Non-communicable diseases) owing to factors involving pollution, access to tobacco and alcohol, processed foods and occupational physical inactivity (Misch,1988 Patel \& Burke,2009).Higher gradient of common NCD risk factors has been found among migrants as compared to rural areas and at a lower risks than urban dwellers (Hernández et al,2012).

Considering the increased risk of lifestyle diseases in populations with rapid nutritional transition and urbanization, it can be predicted that the tribal states of Northeast India have a greater risk. (Khongsdier, 2008). No study has been done to assess the burden of NCD risk factors among Ao Nagas, one of the vulnerable population. Hence an attempt has been made to find out the patterning of different habitat (urban and rural) on the risk factors of developing lifestyle diseases among them.

\section{METHODOLOGY:}

\section{Study population}

1250 Ao Nagas of Nagaland, aged 20-49 yr. The Aos/Ao Nagas are one of the major Naga tribe of Nagaland. They ethnically belong to the Mongoloid stock and linguistically to the Tibeto-Burman group. They follow endogamous, patriarchal, and patrilineal system.

\section{Protocol}

Risk factors were studied using WHO STEPS approach to Surveillance of NCDs. STEPs 1 includes behavioral risk factors like tobacco and alcohol consumption, less than five servings of fruits and vegetables and physical inactivity. STEPs 2 consist of risk factors like overweight, abdominal obesity and hypertension.

Design: Population based cross-sectional study, multi-stage stratified sampling

\section{Setting}

Urban site: Delhi (city) and Mokokchung town; Rural site: Seven villages under Mokokchung district of Nagaland.

\section{Ethical considerations}

The study protocol was approved by the Institutional Ethical committee. Written informed consent was obtained from all the participants prior to commencement of the study.

\section{Inclusion criteria}

Ao Nagas, aged 20-49 years, with no debilitating illness or physical deformity

\section{Exclusion Criteria}

1. Pregnant and lactating mothers

2. Those individuals who have become a member of the Ao Naga tribe through adoption. 


\section{Data collection}

Data was collected from April 2014-April 2016. Purpose and procedure involved in the research was explained to each individual and those who were willing to participate were taken in the study. In Delhi, few individuals came to the Physiological Anthropology Laboratory, University of Delhi for the tests. Door-to-door survey was also carried out for those individuals who couldn't come to the laboratory. In Mokokchung and villages, permission to conduct the fieldwork was taken from the respective district Heads and Village council. Individuals willing to participate in the study were requested to come to the village community halls or primary health centres for the study, however door-to-door sampling was also conducted for those individuals who couldn't come to the respective public centres.

\section{Anthropometric and physiological measurements}

Height, weight and waist circumference were measured using standardized procedures. Height was taken with the help of anthrop meter to the nearest $0.1 \mathrm{~cm}$ in the standard arm hanging position. Body weight was measured by using weighing machine to the nearest $0.1 \mathrm{~kg}$, with minimum clothing. Waist circumference (WC) and hip circumference (HC) were measured with a flexible steel tape to the nearest $0.1 \mathrm{~cm}$ (Weiner \&Lourie, 1981). All the instruments used were calibrated and verified before each assessment. Blood pressure was assessed using standard mercury sphygmomanometer.

\section{Definitions used}

Rural area: defined by villages. Participants were considered under rural area if they were a current resident of a village and had lived there all their life, or those who reported that previously they have been living only in other rural areas (Census, 2011)

Urban areas: Defined by wards. The study participants were clubbed under urban if they were a current resident of Mokokchung town or Delhi and had lived there all their life, or those who reported that previously they have been living in other urban areas prior to coming to Mokokchung/Delhi (Census, 2011).

Current smokers were defined as individuals who had smoked cigarettes, bidis, etc during the last 30 days

Current smokeless tobacco users: Individuals who had used any kind of smokeless tobacco such as chewing tobacco, betel nut, kaka soda etc.

Current alcohol users: Individuals who have consumed an alcoholic drink within the past 30 days.

Binge drinking: $>=5$ standard drinks of alcohol per day for male and $>=4$ standard drinks per day for female

(One standard drink $=285 \mathrm{ml}$ of regular beer/rice beer or $30 \mathrm{ml}$ of spirits)

Physical activity: It was classified according to the MET minutes per week into three groups: High ( $\geq 3000$ MET mins/week), moderate (600-2999 MET mins/week) and low (<600 MET mins/week)

Abdominal obesity markers: Waist circumference $\geq 90 \mathrm{~cm}$ (male) and $\geq 80 \mathrm{~cm}$ (female) (WHO, 2004); WHR :> 0.95 (male) and >0.80 (female) (Dobbelsteyn et al, 2001); WHtR > 0.5 (Willett et al,1999).

Overweight: BMI $\geq 25 \mathrm{~kg} / \mathrm{m}^{2}$ (Ashwell et al, 2012)

Hypertension: SBP ${ }^{\geq} 140 \mathrm{mmHg}$ or $\mathrm{DBP} \geq 90 \mathrm{mmHg}$ or currently taking any medication for hypertension (WHO, 2014)

Combined Risk Factors (WHO, 2010):

The risk factors used to estimate the combined risk are as follows;

a. Current daily smokers

b. Less than five servings of fruit and vegetables per day 
c. Low level of activity (<600METmts/week)

d. Overweight or obese $(\mathrm{BMI} \geq 25 \mathrm{~kg} / \mathrm{m} 2)$

e. Raised Blood pressure (SBP $\geq 140 \mathrm{~mm}$ of $\mathrm{Hg}$ or $\mathrm{DBP} \geq 90 \mathrm{~mm}$ of $\mathrm{Hg}$ or hypertension on treatment)

If $\geq$ Three above mentioned risk factors present, then the person is at high risk.

If $\leq$ Three above mentioned risk factors present, then the person is at low risk.

\section{Statistical analysis}

Data were cleaned and analyzed using SPSS, version 17.0 (SPSS Inc, Chicago,IL). Proportions of risk factors were assessed using the chi-square test. Odds ratios and $95 \%$ confidence interval were calculated for each risk factor using town as reference group by multinomial logistic regression. A value of $p<0.05$ was considered statistically significant.

\section{RESULTS}

Table 1 Distribution of Ao Nagas according to habitat

\begin{tabular}{|l|c|c|c|}
\hline Habitat & Male (\%) & Female (\%) & Total (\%) \\
\hline City (Delhi) & 9.4 & 9.5 & 19.0 \\
\hline $\begin{array}{l}\text { Town } \\
\text { (Mokokchung) }\end{array}$ & 21.6 & 27.9 & 49.5 \\
\hline Village & 4.9 & 16.9 & 31.5 \\
\hline Total & 45.9 & 54.1 & 100 \\
\hline
\end{tabular}

Table 1 highlights the distribution of study participants (Ao Nagas) according to habitat, viz, city (Delhi), town (Mokokchung town of Nagaland) and village (few villages under Mokokchung district of Nagaland. Of the participants, $19.0 \%$ were city dwellers (Delhi), $49.5 \%$ were town dwellers and $31.52 \%$ were village dwellers.

The behavioral risk factors of lifestyle diseases according to WHO STEP1 is displayed in table 2. Current tobacco use was highest amongst the villagers (27.4\%) intermediate in town dwellers(24.7\%) and lowest in city migrants $(16.5 \%)$.However current smokeless tobacco use was highest in the town $(70.3 \%)$ followed by village (67.5\%). Consumption of both form of tobacco was highest among the town residents $(47.5 \%)$. Current alcohol users in city, town and village accounted for $38.4 \%, 27.9 \%$ and $22.8 \%$ respectively. Nevertheless, binge drinkers were observed to be highest among the town dwellers (17.9\%). Intake of less than 5 servings of fruits and vegetables were more prevalent among the villagers $(96.2 \%)$ than the town $(92.4 \%)$ and city dwellers (90\%).Low physical activity were reported as $14.3 \%, 13.1 \%$ and $4.1 \%$ in the city, town and villages. Vigorous physical activity was recorded highest among the villagers (88.3\%). Significant differences were found between gender in the occurrence and distribution pattern of the behavioral risk factors of lifestyle disease except fruits and vegetables intake (all habitat) and physical activity level (city and villages). 
Table 2: Distribution of behavioral risk factors in city, town and village dwellers (WHO STEP 1)

\begin{tabular}{|c|c|c|c|c|c|c|c|c|c|c|c|c|c|}
\hline \multirow[t]{2}{*}{ Variables } & \multicolumn{4}{|c|}{ Delhi } & \multicolumn{4}{|c|}{ Town } & \multicolumn{4}{|c|}{ Village } & \multirow[t]{2}{*}{$x^{2 \#}$} \\
\hline & $\mathrm{M}$ & $\mathrm{F}$ & Total & $\mathrm{x}^{2}$ & $\mathrm{M}$ & $\mathrm{F}$ & Total & $\mathrm{x}^{2}$ & $\mathrm{M}$ & $\mathrm{F}$ & Total & $\mathrm{x}^{2}$ & \\
\hline \multicolumn{14}{|l|}{ Tobacco use } \\
\hline $\begin{array}{l}\text { Current tobacco } \\
\text { use }\end{array}$ & 15.2 & 1.3 & 16.5 & $33.7 * * *$ & 22.5 & 2.3 & 24.7 & $185.7 * * *$ & 26.9 & 0.5 & 27.4 & $153.2 * * *$ & $10.08 * *$ \\
\hline $\begin{array}{l}\text { Current } \\
\text { smokeless } \\
\text { tobacco use }\end{array}$ & 24.5 & 13.9 & 38.4 & $11.4 * * *$ & 34.6 & 35.7 & 70.3 & $19.6 * * *$ & 34.0 & 33.8 & 67.5 & 2.78 & $79.2 * * *$ \\
\hline $\begin{array}{l}\text { Consumption of } \\
\text { any form of } \\
\text { tobacco }\end{array}$ & 29.1 & 14.3 & 43.5 & $21.5 * * *$ & 36.0 & 36.3 & 26.3 & $52.5 * * *$ & 38.1 & 34.0 & 71.8 & $12.3 * * *$ & $71.2 * * *$ \\
\hline $\begin{array}{l}\text { Consumption of } \\
\text { both form of } \\
\text { tobacco }\end{array}$ & 13.9 & 13.1 & 27.0 & 0.11 & 13.4 & 34.1 & 47.5 & $52.8 * * *$ & 11.2 & 33.2 & 44.4 & $62.8 * * *$ & $30.1 * * *$ \\
\hline \multicolumn{14}{|c|}{ Alcohol consumption } \\
\hline Current user & 27.0 & 11.4 & 38.4 & $24.9 * * *$ & 23.3 & 4.7 & 27.9 & $154.6 * * *$ & 20.8 & 2.0 & 22.8 & $89.12 * * *$ & $17.7 * * *$ \\
\hline Binge drinking & 10.5 & 2.1 & 12.7 & $15.4 * * *$ & 16.2 & 1.8 & 17.9 & $119.7 * * *$ & 11.4 & 0.5 & 11.9 & $49.89 * * *$ & $8.08 *$ \\
\hline \multicolumn{14}{|l|}{ Dietary habits } \\
\hline $\begin{array}{l}<5 \text { servings of } \\
\text { fruits and } \\
\text { vegetables }\end{array}$ & 44.7 & 46.0 & 90.7 & 0.21 & 40.4 & 52.0 & 92.4 & 0.19 & 44.9 & 51.3 & 96.2 & 2.30 & $8.56^{* *}$ \\
\hline
\end{tabular}




\begin{tabular}{|c|c|c|c|c|c|c|c|c|c|c|c|c|c|}
\hline \multicolumn{14}{|l|}{ Physical Activity } \\
\hline $\begin{array}{l}\text { Low }(<600 \\
\text { METS-min) }\end{array}$ & 6.8 & 7.6 & 14.3 & 0.95 & 7.1 & 6.0 & 13.1 & $6.81 *$ & 2.3 & 1.8 & 4.1 & 2.99 & $204.6 * * *$ \\
\hline $\begin{array}{l}\text { Moderate(600- } \\
\text { 2999) }\end{array}$ & 27.0 & 24.1 & 51.1 & & 13.6 & 15.7 & 29.2 & & 2.5 & 5.1 & 7.6 & & $204.6 * * *$ \\
\hline $\operatorname{High}(>=3000)$ & 16.0 & 18.6 & 34.6 & & 22.8 & 34.9 & 57.7 & & 42.6 & 45.7 & 88.3 & & $204.6 * * *$ \\
\hline
\end{tabular}

$* \mathrm{p}<0.05, * * \mathrm{p}<0.01, * * * \mathrm{p}<0.001$

Table 3: Distribution of WHO STEP 2 risk factors in city, town and village dwellers

\begin{tabular}{|c|c|c|c|c|c|c|c|c|c|c|c|c|c|}
\hline \multirow[b]{2}{*}{ Variables } & \multirow[b]{2}{*}{$\mathrm{M}$} & \multicolumn{3}{|l|}{ Delhi } & \multirow[b]{2}{*}{$\mathrm{M}$} & \multirow[b]{2}{*}{$\mathrm{F}$} & \multicolumn{2}{|l|}{ Town } & \multirow[b]{2}{*}{$\bar{M}$} & \multicolumn{3}{|c|}{ Village } & \multirow[t]{2}{*}{$\mathrm{x}^{2 \#}$} \\
\hline & & $\mathrm{F}$ & Total & $\mathrm{x}^{2}$ & & & Total & $\mathrm{x}^{2}$ & & $\mathrm{~F}$ & Total & $\mathrm{x}^{2}$ & \\
\hline Overweight & 19.4 & 14.3 & 33.8 & 2.87 & 11.8 & 9.7 & 21.5 & $9.00 * *$ & 8.1 & 10.2 & 18.3 & 0.32 & 21.35 *** \\
\hline \multicolumn{14}{|c|}{ Abdominal obesity } \\
\hline $\mathrm{WC}$ & 8.0 & 7.2 & 15.2 & 0.15 & 4.8 & 8.1 & 12.9 & 1.32 & 3.0 & 7.4 & 10.4 & $6.07 * *$ & 3.23 \\
\hline WHR & 4.6 & 10.1 & 14.8 & $5.53 *$ & 7.4 & 21.6 & 29.1 & $33.10 * * *$ & 7.4 & 22.8 & 30.2 & $36.46 * * *$ & $21.49 * * *$ \\
\hline WHtR & 16.5 & 8.0 & 24.5 & $9.35 * *$ & 12.8 & 10.7 & 23.4 & $9.36 * *$ & 9.6 & 11.2 & 20.8 & .052 & 1.39 \\
\hline Hypertension & 21.5 & 11.8 & 33.3 & $10.33 * * *$ & 22.3 & 13.1 & 35.4 & $52.75 * * *$ & 28.2 & 18.8 & 47.0 & $21.98 * * *$ & $17.07 * * *$ \\
\hline
\end{tabular}

$* \mathrm{p}<0.05, * * \mathrm{p}<0.01,{ }^{* * *} \mathrm{p}<0.001$
$\mathrm{x}^{2} \quad$ indicates chi-square value between gender $; \mathrm{x}^{2 \#}$ indicates chi-square value between Delhi, town and village 
Comparison of the occurrence of risk factors of lifestyle diseases such as overweight, abdominal obesity and hypertension among the city migrants, town dwellers and villagers are given in Table 3 as assessed by WHO STEP2.Occurence of overweight was highest in the city $(33.8 \%)$ than the town $(21.5 \%)$ and the villages (18.3\%). Abdominal obesity measured by WC and WHtR showed highest risk among the city dwellers while WHR showed highest risk among the villagers. Villages recorded highest occurrence of hypertension (47\%) followed by town (35.4\%) and city (33.3\%). Males were found to be mostly hypertensive than females irrespective of the habitat.

Significant difference in the occurrence of STEP 2 risk factors of lifestyle diseases were observed between the three different habitats.

Table 4: Risk of lifestyle diseases in city and village dwellers with town dwellers as reference group

\begin{tabular}{|c|c|c|}
\hline City (Delhi) & & Village \\
\hline Variables & OR(95\% CI) & OR(95\% CI) \\
\hline Current smoking tobacco user & $\mathbf{- 0 . 4 5 4} * *(0.251-0.821)$ & $1.310(.836-2.053)$ \\
\hline Non user & $0^{\mathrm{b}}$ & $0^{\mathrm{b}}$ \\
\hline $\begin{array}{l}\text { Current smokeless tobacco user } \\
\text { Non user }\end{array}$ & $\begin{array}{l}-.142 * * *(0.052-0.390) \\
0^{\mathrm{b}}\end{array}$ & $\begin{array}{l}-.601 *(.254-1.425) \\
0^{\mathrm{b}}\end{array}$ \\
\hline $\begin{array}{l}\text { Current alcohol user } \\
\text { Non user }\end{array}$ & $\begin{array}{l}\mathbf{5 . 1 8 0} * *(3.162-8.499) \\
0^{\text {b }}\end{array}$ & $\begin{array}{l}-.754(.496-1.144) \\
0^{\mathrm{b}}\end{array}$ \\
\hline $\begin{array}{l}\text { Binge drinkers } \\
\text { Non binge drinkers }\end{array}$ & $\begin{array}{l}-0.483(0.272-0.857) \\
0^{\mathrm{b}}\end{array}$ & $\begin{array}{l}-.601(.371-.972) \\
0^{\mathrm{b}}\end{array}$ \\
\hline $\begin{array}{l}\text { Abdominal obesity } \\
\text { WC Risk } \\
\text { Normal }\end{array}$ & $\begin{array}{l}1.486(.682-3.239) \\
0^{\mathrm{b}}\end{array}$ & $\begin{array}{l}-.690(.369-1.288) \\
0^{\mathrm{b}}\end{array}$ \\
\hline $\begin{array}{l}\text { WHR Risk } \\
\text { Normal }\end{array}$ & $\begin{array}{l}-\mathbf{0 . 3 1 3} * * *(.179-.547) \\
0^{\mathrm{b}}\end{array}$ & $\begin{array}{l}1.070(.737-1.552) \\
0^{\mathrm{b}}\end{array}$ \\
\hline $\begin{array}{r}\text { WHtR Risk } \\
\text { Normal }\end{array}$ & $\begin{array}{l}-0.524(.253-1.088) \\
0^{\mathrm{b}}\end{array}$ & $\begin{array}{l}-.889(.514-1.538) \\
0^{\mathrm{b}}\end{array}$ \\
\hline $\begin{array}{l}\text { Hypertensive } \\
\text { Non-hypertensive }\end{array}$ & $\begin{array}{l}-0.895(.586-1.368) \\
0^{\mathrm{b}}\end{array}$ & $\begin{array}{l}\mathbf{1 . 7 0 9} * * *(1.242-2.352) \\
0^{\mathrm{b}}\end{array}$ \\
\hline
\end{tabular}




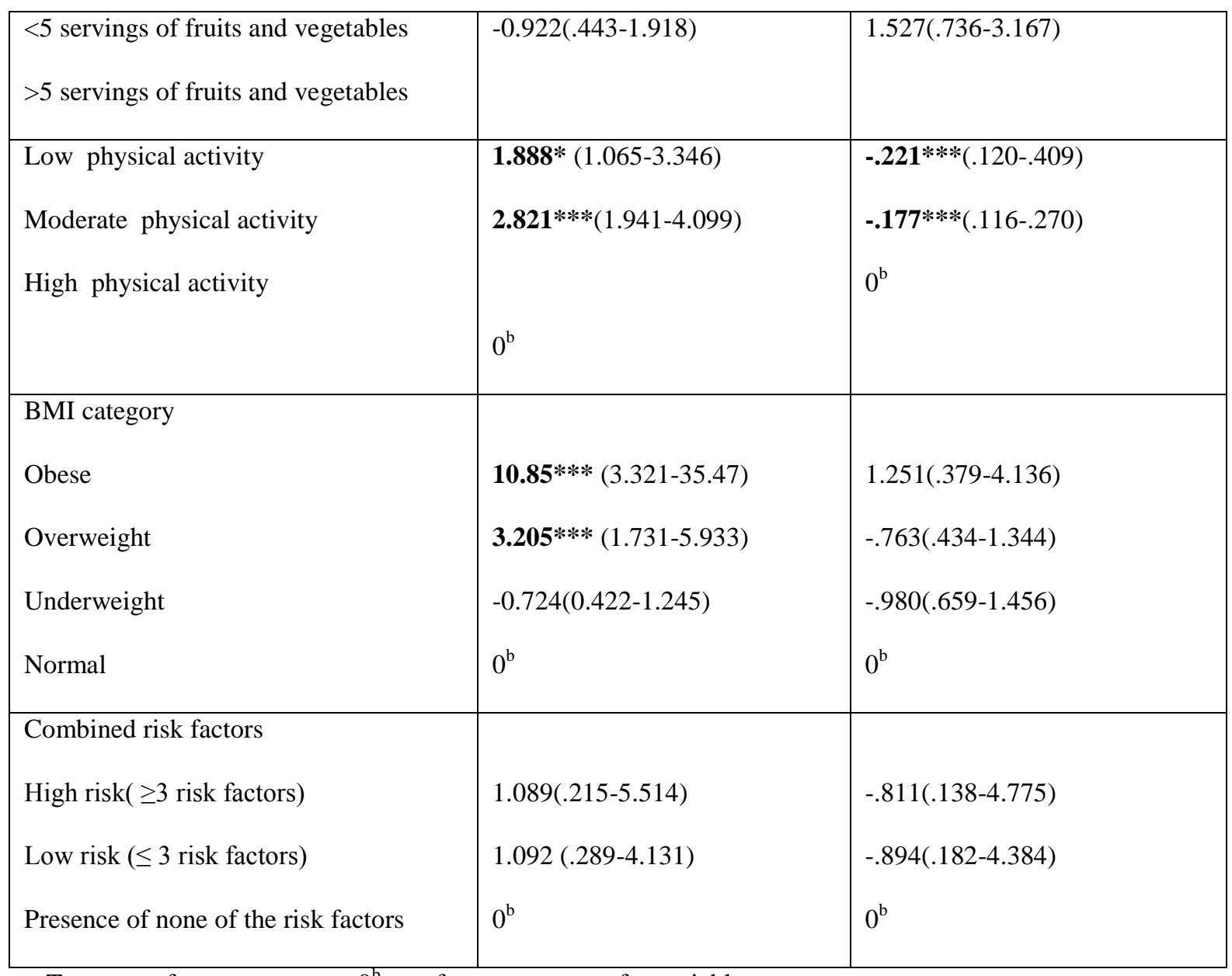

Town as reference category, $0^{b}$ as reference category for variables

${ }^{*} \mathrm{p}<0.05, * * \mathrm{p}<0.01, * * * \mathrm{p}<0.001$

Table 4 displays comparative analysis between various risk factors of lifestyle diseases and habitat (City vs town; village vs town)

Smoking: Current smoking tobacco users were significantly ( 0.45 times) less likely to be found in city than town as compared to those who were non-smokers. Current smokeless tobacco users were significantly ( 0.14 and 0.60 times) less likely among city vs town dwellers and village vs town dwellers as compared to those who did not use smokeless tobacco products.

Alcohol consumption: Current alcohol users were significantly (5.18 times) more likely among city migrants than town dwellers and (7.54 times) less likely in village than town as compared to non-alcohol users. Binge drinkers as compared to non-binge drinkers were more likely to be found among town dwellers than city and village dwellers.

Abdominal obesity: In city, individuals were significantly found to be 0.31 times less abdominally obese than town dwellers who were not abdominally obese as assessed by WHR.

Hypertension: Villagers were significantly (1.70 times) more likely to be hypertensive than town dwellers as compared to non-hypertensive. City dwellers were 0.89 times less likely to be hypertensive than town dwellers as compared to non-hypertensive's. 
Diet: City dwellers were 0.92 times less likely to consume less than 5 servings of fruits and vegetables than their town counterparts. However villagers were 1.52 times more likely to consume less than 5 servings of fruits and vegetables than town dwellers. This indicates that villagers were more likely to consume less than 5 servings of fruits and vegetables than the town and city dwellers.

Physical activity: People were significantly found to be 1.88 and 2.82 times more likely engaged in low and moderate physical activity than vigorous activity among city than town dwellers. However, villagers were significantly found to be 0.22 and 0.77 times less likely to be engaged in low and moderate activity than town dwellers.

Overweight and obesity: The proportion of obesity and overweight individuals was 10.8 and 3.20 times significantly higher than normal BMI individuals in city than town dwellers. Proportion of overweight was 0.76 times lesser than normal BMI individuals in villages as compared to town.

Combined risk factors: In city, individuals were 1.08 times more likely to be under high risk groups ( $>=3$ risk factors) than town dwellers as compared to those individuals who had none of the risk factors. High risk groups were 0.8 times less likely to be found among villagers than town dwellers.

\section{DISCUSSION}

Risk factor profile of lifestyle disease as assessed by the WHO STEPs approach among the same ethnic population inhabiting city and town dwellers were not pragmatically worse than the village dwellers. Low physical activity, overweight, obesity and alcohol consumption among city dwellers; tobacco consumption, raised WHR and low physical activity among town dwellers; hypertension among the villagers were found to be independent risk factors of lifestyle diseases. High risk groups were more likely to be prevalent in the city $(1.089(.215-5.514)$, intermediate in town and lowest in the village $(811(.138-4.775)$.

Current tobacco use of both smoking and smokeless tobacco was highest in the town, but current smoking tobacco users were highest in the villages (27.4\%). Consumption of smokeless tobacco was more than the use of smoking tobacco as the latter was mostly confined to the male gender whereas smokeless tobacco such as betel nut, paan, gutkha, etc were frequently consumed by both the gender. Proportion of males consuming both forms of tobacco was observed to be more among the male respondents in the city and village. City migrants were less likely to smoke and use smokeless tobacco products than rural groups as reported by some studies in China and India. Possible reason may be due to frequent exposure of tobacco related health adversities advertisement in urban areas (Ebrahim et al, 2010).

Current alcohol use was significantly higher in the city than the town and village areas (Girish et al, 2010). However binge drinking was more frequent among the town residents. Cultural and societal norms in the village and town restrict the consumption of alcohol by the womenfolk, as such, higher percentage of women was found to consume alcohol in the city than the counterparts. Moderate consumption of alcohol was observed among the city residents but alcohol abuse amongst males was mostly seen among the town and village residents.

Consumption of less than five servings of fruits and vegetables were highest among the villagers than the urban groups. Although the villagers were more accessible to locally grown fresh fruits and vegetables all year round, most of them generated income by selling it in the market which ultimately lead them to consume less servings. This finding is in consistent with the study done by Shah and Mathur (2010). Fewer intakes of fruits and vegetables were consistently found to be lesser among males in the three habitats.

Both low and moderate physical activity was significantly lower in the urban areas (city and town) than the rural area (Ojiambo et al, 2012).

Villagers were also found to be engaged more in vigorous physical activities like working in the fields, hunting, fishing, daily wage labor, etc. Rural dwellers having higher physical activity has also been reported in Tamil Nadu, India and Missing tribe of Assam (Allender et al,2010); (Palash et al,2014). Males 
were found to be less physically active than females in both urban and rural areas. Leisure time physical activity was more frequent among those who reside in the city and the town.

Overweight and obesity were significantly found to be highest in the city. This finding is consistent with the cross-sectional study of the WHO-SAGE data on rural, urban and migrant differences in NCD risk factors in middle income countries and other studies (Stuckler et al, 2010); (BeLue et al, 2009). This may be due to increase in calorie intake with lower level of occupational physical activity and sedentary behaviors in city migrants leading to difference in energy balance. Systematic review by Hernandez et al (2012) on the effect of rural urban migration on CVD risk factors in low and middle income countries also reported high prevalence of overweight and obesity in urban than rural areas and also found no association between migration and hypertension. This study also found that hypertension was significantly high in rural area (village) than the urban areas (city and town) indicating no association with migration.This may also reflect the possibility of rapid urbanization in the villages. Hypertension was more prevalent among the males in all the studied habitat. Abdominal obesity assessed by WHR was significantly higher in town dwellers than the city migrants, but WC and WHtR showed more abdominally obese individuals in the city.

Traditionally, the main occupation of the Ao Nagas was agriculture-both terrace and wetland farming, followed with animal husbandry, sources of wealth from forest and river. Western education was embraced by the Aos with the advent of Christianity in the $19^{\text {th }}$ century and at present they are the most literate tribe in Nagaland. Slowly, with the advent of urbanization, economic development and capitalist market competition, most of them shifted to modern professions (that requires less of physical activity) like public and private jobs, business, etc. although farming still remains the primary occupation among the villagers. Less physical activity like walking less and travelling more by vehicles, sitting for longer hours infront of computers and TV are rampant among the Gen Y and Z. The staple food of Ao Nagas is rice and meat (especially pork considered having highest content of fats), the latter itself is a risky aspect for developing NCDs. Aggravating this situation is the recent penetration of increasing outlets of fast food restaurants and food chains. Consumption of 'Rice bear' (locally fermented liquor) has become less frequent with the penetration of market-branded liquor (Rum). Traditional chewing of areca nut with betel leaves and smoking tobacco is accompanied with both forms of market-branded tobacco products (gutkha, cigarettes, etc). Inactive lifestyle, nutrition transition and substance abuse are rapidly trending among the Ao Nagas . They are found to be indulged in less consumption of tobacco products with increased consumption of alcohol and processed food and sweetened drinks post migration to the city. Sedentary hours and frequency of eating out also increased among the migrants.

Data was collected using objective measures and tools of anthropometry and physiological parameters. But many outcome measures, especially behavioral risk factors such as consumption of alcohol and tobacco and physical activity were self-reported, hence maybe subject to under-and-over-estimation and social desirable biases. Comparison of socio-economic, psychological stress and in depth study on dietary habits between the different habitats would provide a clearer picture of the patterning of the NCD risk factors. Period of exposure to the urban environment and inter- intra-urban movements could not be ascertained in the study.

\section{CONCLUSION}

This study calls for careful implementation of different strategies to combat the burden of lifestyle diseases in the population both in rural and urban areas Difference in risk profile groups should be identified considering the socio-cultural issues and specific intervention should be targeted integrated at primary healthcare sector. Comprehensive approach should be utilized as lifestyle diseases are not caused by a single risk factor. Market penetration of smokeless tobacco products in town and villages should be a concern for the policy makers. Binge drinking and alcohol abuse in the population despite Nagaland been declared as a 'Dry state' warrants rigorous and timely health intelligence for adopting prohibitive measures. Occupational interventions of physical activity among the city and town dwellers could be a cornerstone for lifestyle modification.

\section{ACKNOWLEDGMENTS}

The authors are grateful to all the respondents, District Heads and respective Village councils of Mokokchung district of Nagaland for giving permission to collect the data; Delhi Ao Baptist church, 
friends and siblings who assisted in logistics in carrying out the fieldwork. Fellowship given to IP by University Grants Commission to carry out the research is highly acknowledged.

\section{REFERENCES}

1. Allender S, Lacey B, Webster P, Rayner M, Deepa M, Scarborough P,etal.(2010). Level of urbanization and non-communicable disease risk-factors in Tamil Nadu, India. Bulletin of the World Health Organization; 88(4):297-304.doi:10.2471/BLT.09.065847PMID:20431794]

2. Ashwell M, Gunn P, Gibson S. (2012).Waist-to-height ratio is a better screening tool than waist circumference and BMI for adult cardiometabolic risk factors: systematic review and metaanalysis. Obes Rev ,13:275-286.

3. BeLue R, Okoror TA, Iwelunmor J, Taylor KD, Degboe AN, et al. (2009). An overview of cardiovascular risk factor burden in sub-Saharan African countries: a socio-cultural perspective. Global Health, 5: 10. doi:10.1186/1744-8603-5-10.

4. Census of India. (2011). Retrieved from http: //censusindia.gov.in/ 2011-prov results/ paper2/ data_files/India2/ 1.\%20Data\% 20Highlight. Pdf

5. Detels R., Mc Ewen J., Beaglehole R. et al.(2002). Oxford Textbook of Public Health -The Scope of Public Health .4th edition. Oxford: Oxford university press. 115-30p.

6. Dobbelsteyn C. J., Joffres M. R., MacLean D. R., Flowerdew G. (2001). A Comparative Evaluation of Waist Circumference, Waist-to-hip Ratio and Body Mass Index as Indicators of Cardiovascular Risk Factors. The Canadian Heart Health Surveys. Int. J.Obes Relat Metab Disord, 25(5): 652-61.

7. Ebrahim S, Kinra S, Bowen L, Andersen E, Ben-ShlomoY,Lyngdoh T,etal. (2010).The effect of rural-to urban migration on obesity and diabetes in India: a cross-sectional study. PLoSmedicine, 7(4): e1000268+doi: 10.1371/journal. pmed. 1000268PMID: 20436961

8. Girish, N., Kavita, R., Gururaj, G., \& Benegal, V. (2010). Alcohol Use and Implications for Public Health: Patterns of Use in Four Communities. Indian Journal of Community Medicine: Official Publication of Indian Association of Preventive \& Social Medicine,35(2), 238-244. http://doi.org/10.4103/0970-0218.66875

9. Harpham T. (2009).Urban health in developing countries: What do we know and where do we go? Health and Place, 15(1), 107-116.doi:10.1016/j.healthplace.2008.03.004PMID:18455952

10. Hernández AV, Pasupuleti V, Deshpande A, Bernabé-Ortiz A, MirandaJJ. (2012). Effect of ruralto-urban within-country migration on cardiovascular risk-factors in low-and middle-income countries: a systematic review. Heart, 98(3):185-194.doi:10.1136/heartjnl-2011300599PMID:21917659

11. Khongsdier R.(2008). Increasing urbanization in tribal states of Northeast India; implication for the prevalence of chronic diseases. Tribes and Tribals, In: Bose K, editor. Health and nutritional problems of indigenous population. New Delhi: Kamal Raj Enterprises; p. 25-33

12. Misch KA. (1988). Ischaemic heart disease in urbanized Papua New Guinea. Anautopsystudy.Cardiology,75(1):71-75.PMID:3342427

13. Murray CJL, Vos T, Lozano R, Naghavi M, Flaxman AD, Michaud C, et al. (2012).Disability adjusted life years (DALYs) for 291 diseases and injuries in 21 regions, 1990-2010: a systematic analysis for the Global Burden of Disease Study 2010. Lancet,380(9859):219-23.

14. Ojiambo RM, Easton C, Casajús JA, Konstabel K, Reilly JJ, Pitsiladis Y.(2012).Effect of urbanization on objectively measured physical activity levels, sedentary time, and indices of adiposity in Kenyan adolescents. $J$ Phys Act Health, 9: 115-23.

15. Palash Jyoti Misra, G.K. Mini \& K.R. Thankappan. (2014).Risk factor profile for noncommunicable diseases among Mishing tribes in Assam, India: Results from a WHO STEPs survey. Indian J Med Res, 140, pp 370-378

16. Patel RB, Burke TF.( 2009). Urbanization- an emerging humanitarian disaster. The New England journal of medicine, 361(8): 741-743. doi: 10.1056/ NEJMp0810878PMID: 19692687

17. Shah B, Mathur P. (2010). Surveillance of cardiovascular disease risk factors in India: The need \& scope. Indian J Med Res ,132: 634-42.

18. Stuckler D, Basu S, McKee M. (2010). Drivers of inequality in Millennium Development Goal progress: a statistical analysis. PLoS Med,7: e1000241. doi:10.1371/journal.pmed.1000241.

19. Weiner JS, Lourie JA. (1981).Practical Human Biology. New York: Academic. 
20. Willett W.C., Dietz W.H. and Colditz G.A. (1999). Guidelines for healthy weight. New England Journal of Medicine, 341:427-434.

21. WHO Expert Consultation.(2004).Appropriate BMI for Asian population and its implications for policy and intervention strategies.Lancet,363:157-163.

22. WHO (2010). Mangolian STEPS Survey on the prevalence of non- communicable disease and injury risk factors-2009: Geneva

23. World Health Organization. Non-communicable diseases [homepage on the Internet].(2014). Available from: http: //www. who. int/ mediacentre/ factsheets/ fs355/en/. [Accessed on 2014 Jan 23]. 